\title{
Research on the Management Optimization of Industry- University-Research Cooperation Projects in Colleges and Universities from the Perspective of Collaborative Management
}

\author{
Xizhen Wang ${ }^{1, a}$ \\ ${ }^{1}$ National Institute of Education, Nanyang Technological University, Singapore city, Singapore \\ ${ }^{\mathrm{a}}$ wangxizhensqcg@outlook.com
}

\begin{abstract}
Actively launching industry-university-research cooperation projects in colleges and universities is an effective way to build an innovative country. The optimization of collaborative management of industry-university-research cooperation projects in colleges and universities determines whether scientific and technological achievements can be quickly transformed into real productive forces and whether the construction of an innovative country can be accelerated. Formulating scientific and reasonable policies, optimizing incentive strategies, risk management and benefit distribution, as well as optimizing personnel management, production management, and collaborative innovation knowledge management are conducive to improving the management efficiency of industry-university-research collaborative innovation and promoting the process of building an innovative country.
\end{abstract}

Keywords: Collaborative management, Industry-university-research cooperation, Management optimization.

\section{Connotation of Industry-University- research Collaborative Management}

(1) Industry-university-research collaborative management is oriented by user and market demand. The purpose of industry-university-research collaboration is to coordinate resources of all parties to promote technological innovation, develop competitive advantages of enterprises and create their core competitiveness, so as to boost the sustainable development of enterprises. It takes users and market demand as the orientation, conducts pulling operation, carries out market research, technology research and development, and applies the results of the industry-university-research into the practice of enterprises and related users. (2) Industryuniversity-research collaborative management takes industry and enterprise as the subjects. Industry is composed of enterprises which are the driving force to promote the development of market economy, the subject of market innovation, and the most important market players; besides, enterprises are the main body closest to market demand, who have the best understanding of innovation demand, get better insight into market demand, identify the direction of technological innovation, and have the most internal need to transform innovation results into reality, so as to promote the success of industry-university-research-use cooperation. (3) The industry-university-research-use collaborative management is supported by colleges and universities who are knowledge producers and talents providers, playing an important role in the cultivation of talents and the integration and spread of knowledge. Under the industry-universityresearch collaborative management, the talent resources, knowledge resources and scientific and technological achievements of colleges and universities are seamlessly connected with enterprises and the market, as well as the scientific and technological service ability and talent training ability of colleges and universities are constantly improved according to the feedback of enterprises and the market.(4) The key role of industry-university-research collaborative management is to be promoted and guided by the government. In the industry-university-research-use collaborative management, the government plays a significant promoting and guiding role. [1]

The basic structure and connotation analysis of industryuniversity-research-use collaborative management are shown in Figure 1.

\section{Interest Demands Between Participants of Industry-University- Research Cooperation Projects}

Industry-university-research can usually include industry, teaching and research, involving enterprises, colleges and universities, research institutions and governments. Participants have different interests and social responsibilities, but this innovative way of cooperation benefits all. Enterprises expect technical support from colleges and universities to provide theoretical support for innovation [2], while expecting reduction of innovation cost from the government to accelerate the process of industrial innovation. Colleges and universities hope to get the opportunity of theoretical application, the latest progress of the industry, and some research and development funds from enterprises, while longing for more opportunities of similar cooperation and certain scientific research funding from the government. The government wishes to find a driving force for local economic development from the industry-university cooperation between enterprises and universities, and explore a breakthrough for the development and transformation of local industries. Guided by the interests of the whole society and industry, the government hopes to support and guide the effective development of industry-university-research collaborative innovation. [3]

For enterprises, once the technical support provided by 
universities is suddenly withdrawn, it is easy for them to lose their hard-earned cooperative relationship. For colleges and universities, on the one hand, they yearn for more practical opportunities, especially practical theories as new as possible and as deep as possible. On the other hand, the financial support from enterprises is also the economic foundation for scientific research and innovation. How to prevent enterprises from "running away" after acquiring technologies is also a problem that universities and enterprises often encounter in cooperation. To solve this problem, a third party should also be involved to firmly manage both sides, so that the economic path cannot be interrupted, and more professional institutions and enterprises can be entrusted to seek opportunities of hightech transformation. For governments, the most pressing thing is to know what kind of regional economic benefits and development impetus a partnership can bring, so that taxpayers' money is well spent. [4]

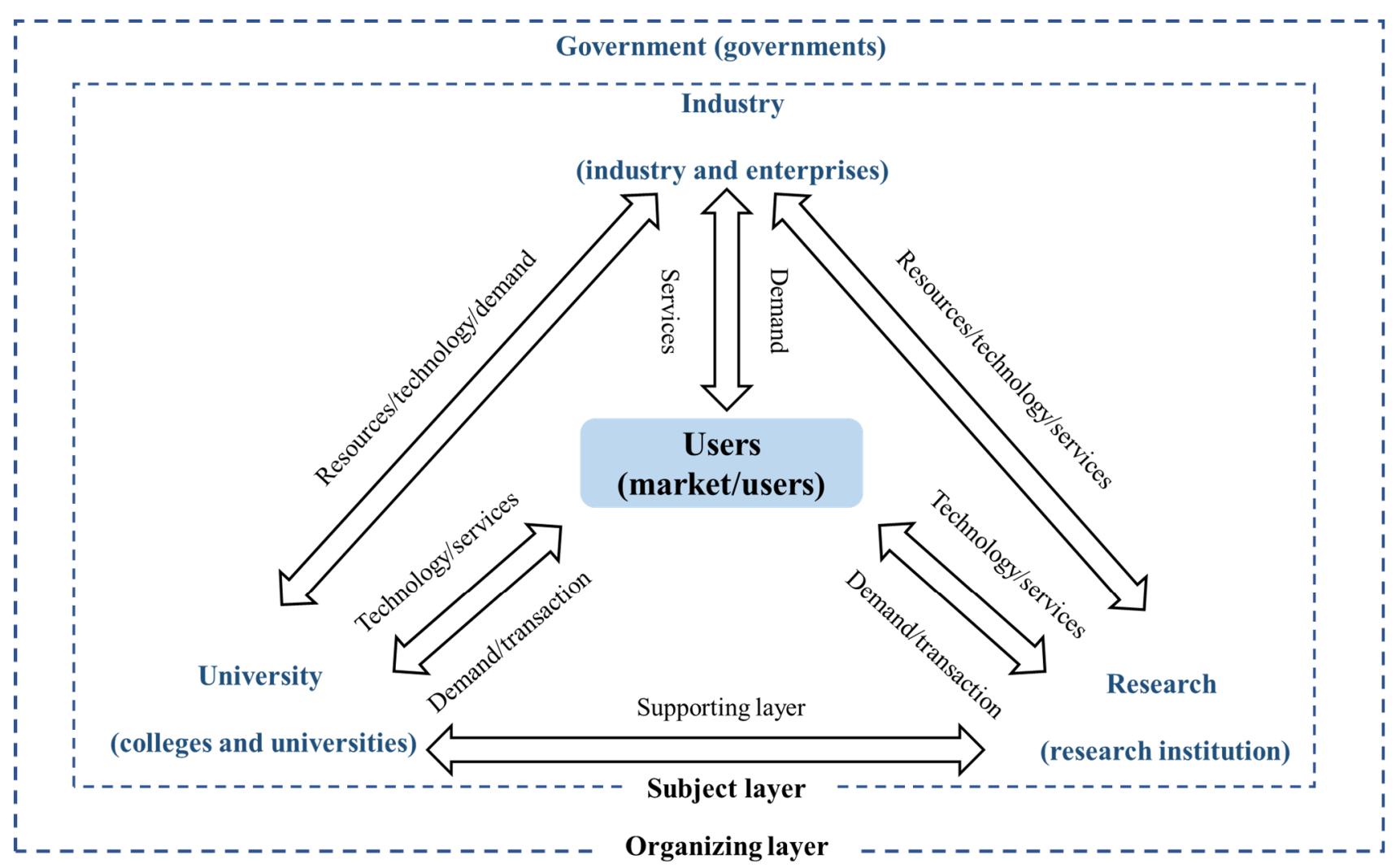

Figure 1. Basic Structure and Connotation Analysis of Industry-University-Research-Use Collaborative Management

\section{Improving Incentive Strategy, Risk Management, Benefit Distribution and Constraint Mechanism}

\subsection{Highlighting Technological Innovation Incentives}

In the industry-university-research collaborative innovation mechanism, science and technology should be constantly innovated, and all parties should maximize and rationalize the enthusiasm of their internal employees in the process of cooperation, so as to realize scientific and efficient cooperation benefits. In the course of continuous technological progress, incentive strategies should be continuously implemented in the entire industry-universityresearch collaborative innovation system. [5] For example, enterprises implement economic incentives to improve the enthusiasm of their employees, and universities improve the enthusiasm of researchers through incentives such as title and salary awards.

\subsection{Implementing Risk Sharing by All Parties}

In the industry-university-research collaborative innovation cooperation organization, certain brand risks will occur after the organization is established, and risks can be dealt with by signing contracts through legal means and certain economic means, so as to realize risk sharing, strengthen the trust between all parties and protect the brand interests of industry-university-research collaborative innovation. Among them, the brand risk sharing contract actively shares the brand, closely links all parties with the brand as the media, realizes the rational use of brand resources, and establishes a scientific trust mechanism within the industry-university-research collaborative innovation cooperation organization. [6].

\subsection{Ensuring the Distribution of Benefits}

Industry-university-research collaborative innovation organization is to maximize the interests of all parties. The benefits of all parties are distributed according to the cooperation content, and the those obtained by the cooperation organization are distributed according to the input of the personnel of all parties. They need to coordinate and communicate to reach consensus, recognize the common interests of the parties, and realize the scientific benefit distribution of all parties.

\subsection{Improving the Constraint Mechanism}

The purpose of all parties of industry-university-research collaborative innovation cooperation is to increase their own value, keep a rational economic mind, and avoid unnecessary waste of transaction costs. All parties continuously improve 
the restraint mechanism, and should increase the collaboration of vertical process and standardize the collaboration of horizontal process. Vertical process collaboration mechanism refers to the innovation cooperation in accordance with the supply chain model, with the supply chain of the core enterprise as the first, and continuously develop to the R\&D and market of collaborative innovation.[7]By improving the production and management of the supply chain, with the help of scientific knowledge and technology, collaborative organization innovation can achieve synergies. Standardization of horizontal process collaboration refers to the communication of all parties in the process of technological research and development and product production, to reach consensus on the opinions of all parties and simplify the complex horizontal process. These two constraint mechanisms can effectively reduce transaction costs and maximize the benefits of industry-universityresearch collaborative innovation.

\section{Optimizing Personnel Management and Production Management}

In the university-enterprise cooperation, the original management mode of universities and enterprises faces new challenges. The problems of personnel management mainly include coordination of work system and labor fee; the problems of production management mainly contain coordination of project schedule and division of work. To solve these problems, management needs to be optimized from the following aspects:

4.1 The working system should be optimized and flexible working system should be advocated. On the premise of daily attendance on time, university personnel give priority to engineering projects during their working hours, and can complete the scientific research tasks of the university at their own disposal. This not only solves the safety management problem of teachers and students in most of the time, but also coordinates the self-balance between engineering projects and scientific research projects.

4.2 The labor fee should be the same as that of interns, but the labor fee should be quantified on a project basis.

4.3 Schedule coordination of the project shall ensure that individuals' R\&D progress of the project will not lag behind the overall engineering $R \& D$ progress of the enterprise. However, the schedule planning should be controlled by senior experts, not by individuals to determine the progress of sub-projects, but by experts to make unified scheduling.

4.4 The coordination of the division of work still needs to be controlled by senior experts to clarify the respective tasks of enterprise engineers and teachers and students in colleges and universities, so as to minimize cross-projects and repetitive workload, but it is necessary to ensure essential cooperation tasks and smooth knowledge exchange between the two sides.

\section{Industry-university-research Collaborative Innovation Knowledge Management}

Many problems have been found in the knowledge exchange of industry-university-research cooperation projects in colleges and universities, summarized as follows: difficulty in knowledge classification, difficulty in engineering mastery, difficulty in theoretical self-study and difficulty in application of theory into practice. The difficulty in knowledge classification is reflected in the hierarchical classification of theories in books and theories contained in practice during the learning process. It is easy to face profound problems as soon as one gets started, which leads to low learning autonomy and enthusiasm. And it is difficult to maintain motivation for learning as it is hard to get positive feedback on learning without gradual progress. The difficulty in engineering mastery is reflected in the fact that universities cannot quickly get familiar with the software and hardware used in engineering at the beginning in practice, resulting in a waste of time in the first step. Then, the difficulty in theoretical self-study is reflected in the fact that engineers are mainly self-taught when learning theoretical knowledge, and cannot quickly grasp the key points. The difficulty in application of theory into practice is the most common problem in the combination of theoretical practice. They fail to know how to use theory to guide practice, nor do they understand the theory contained in engineering practice. [8]

In order to solve the above four problems, solution will be proposed to both sides of the cooperation respectively. Colleges and universities provide high-level faculty with experience in enterprise practice to classify knowledge levels. Because of the relevant experience of enterprise practice and the familiarity with knowledge system in the university environment, it is easy and fast to provide systematic knowledge hierarchy for both the university and the enterprise who have learning needs, so that both sides can learn efficiently from easy to difficult. In the meantime, enterprises provide experienced engineers to guide on the front line, so that the university can quickly get familiar, and master the necessary operation skills. Universities specify teachers and students with profound theoretical knowledge to do a series of training, and invite academic majors to give relevant lectures. In this way, enterprise engineers can not only obtain the basic knowledge of key points and guidance, but also have a preliminary exploration of relevant knowledge as well as grasp the direction of academic development. Enterprises offer senior R \& D engineers to guide, with their own comprehensive knowledge to teach related personnel how to apply the theory into practice. Research and development backbone's understanding of practice and theory helps both sides interact in learning, making the combination of theory and practice more efficient and targeted. (Figure 2) 


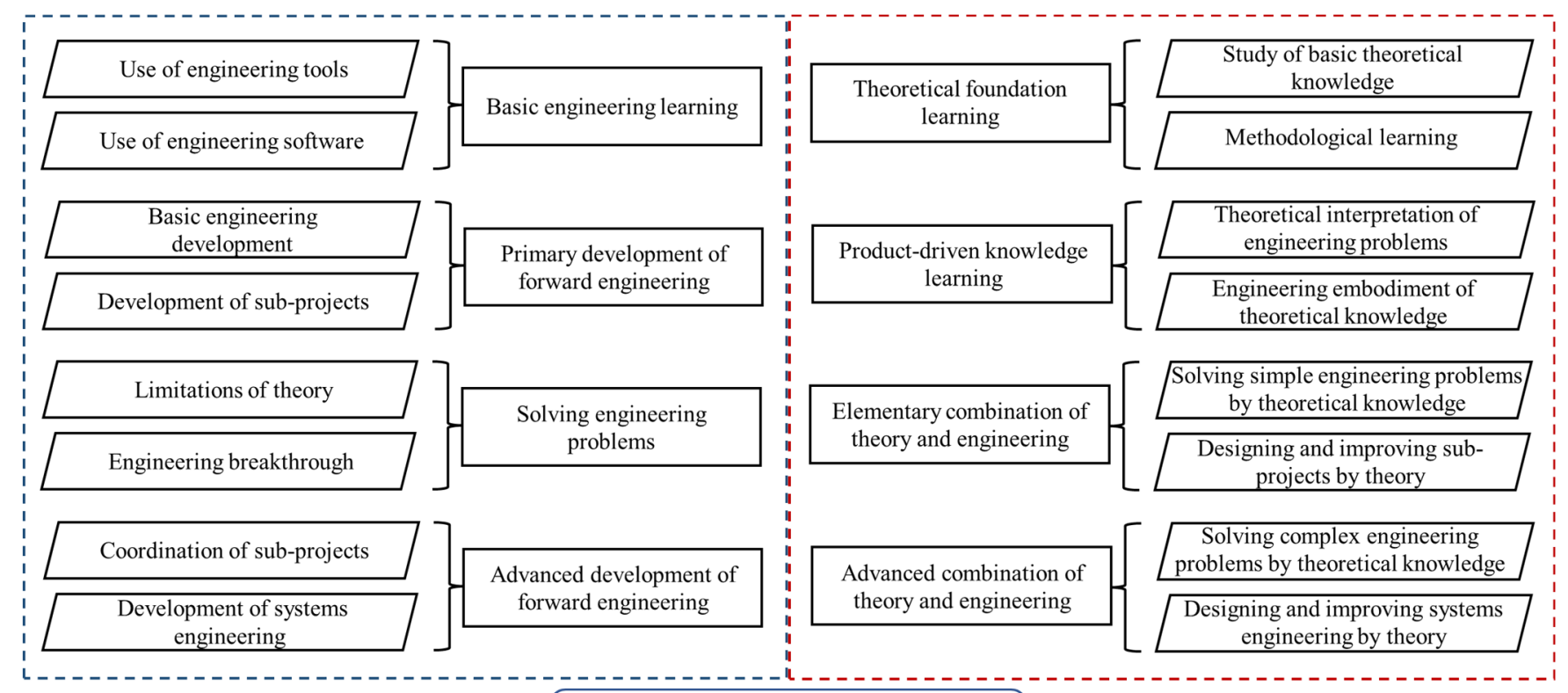

\section{Cooperative development}

Figure 2. Learning Hierarchy Between Universities and Enterprises

As for the hierarchy of knowledge, we divided the learning of universities and enterprises into five levels, as shown in Figure 1. The classification of product-driven knowledge learning of teachers and students in colleges and universities includes basic engineering learning, primary development of forward engineering, solving engineering problems, advanced development of forward engineering, and cooperative development. The classification of theoretical knowledge learning of enterprise engineers includes theoretical foundation learning, product-driven knowledge learning, primary combination of theory and engineering, advanced combination of theory and engineering, and cooperative development. The first four steps not only enable them to learn what they need, but also help each other understand their counterpart's knowledge domain and division of labor, which can improve the efficiency and fault tolerance rate in the process of innovation collaboration. The last cooperative development is the two sides each play their own roles; enterprise engineers mainly deeply explore engineering practice, but different from before, they should discover the theoretical knowledge contained in practice; teachers and students in universities are focused on theoretical innovation, and compared with the past, they also need to think about what kind of technology is suitable for the current engineering development. Both sides should offer their engineering and theoretical insights to the other to help their counterpart do better and achieve a win-win situation.

\section{References}

[1] CHEN Wei,WANG Xiufeng,LI Jinqiu,LI Mingqiu.Research on dynamic selection model of cooperative partners in industry-university-research

collaboration
innovation[J].Journal of Harbin Engineering University,2020, 41(11):1727-1734.

[2] Ida D'attoma; Silvia Pacei; Giorgio Tassinari.Drivers of Cooperative Innovation between Business and Science. The Case of Germany[J]. International Journal of Business Innovation and Research,2021(26):163-193.

[3] Silvia Mazzetto.A practical, multidisciplinary approach for assessing leadership in project management education[J].Journal of Applied Research in Higher Education,2019(11):50-65.

[4] CHEN Yongqiang,ZHANG Wen,JIN Chunhua.Study on Building a Platform of Government- Industry UniversityInstitute Cooperative Innovation in Construction Project Management[J].Science and Technology Management Research,2012, 32(22):243-246.

[5] Kyunam Kim.Impact of Firms' Cooperative Innovation Strategy on Technological Convergence Performance:The Case of Korea's ICT Industry[J]. Sustainability,2017(09):1601.

[6] Huang Xiaoxia,Yu Shuangyang,Ding Ronggui.Impact on Project Management Performance of the Field Cognitive Style of Industry-University-Institute Cooperation Project Managers[J].Science \& Technology Progress and Policy,2016, 33(5):22-27.

[7] LeiYang,RanChen,GuishengHou.The quantitative evaluation of the social benefits of University-Industry cooperative innovation based on CVM[J]. Journal of Residuals Science \& Technology, 2016(13):6.

[8] ZHANG Yongsheng.Construction of Operation Mechanism of Industry-University-Research Cooperation Platform for Highend Equipment Manufacturing Enterprises [J]. Value Engineering,2020, 39(30):177-178. 